\title{
GSTM1 and GSTT1 Genetic Polymorphisms and Breast Cancer Risk in Selected Filipino Cases
}

\author{
Noel Angelo Kalacas ${ }^{1,2 *}$, Julius Adrie Garcia ${ }^{1,2}$, Teresa Sy Ortin ${ }^{3}$, Alfredo Valdez \\ Jr$^{4}$, Allan Fellizar ${ }^{1,4}$, Maria Cristina Ramos ${ }^{1,2,5}$, Pia Marie Albano ${ }^{1,2,5}$
}

\begin{abstract}
Background: The association of genetic polymorphisms with cancer development has been shown to be race- and tumor site-specific. Thus, this study aimed to determine whether polymorphisms in the GSTM1 and GSTT1 genes are associated with breast cancer among selected Filipinos. Methods: A total of 136 histologically confirmed breast cancer cases were age- and sex-matched with 136 clinically healthy controls. Genomic DNA extracted from blood samples of participants were screened for GSTM1 and GSTT1 genetic polymorphisms by multiplex PCR. Results: The frequency of null genotypes among the cases (GSTM1: $\mathrm{n}=78 ; 57.4 \%$; GSTT1: $\mathrm{n}=61 ; 44.9 \%$ ) was not significantly different ( $\mathrm{p}>0.05$ ) from the controls (GSTM1: $\mathrm{n}=93 ; 68.4 \%$; GSTT1: $\mathrm{n}=59 ; 43.4 \%$ ). It was also demonstrated that risk for breast cancer was increased in passive smokers carrying the GSTM1 null (OR=2.56; 95\% CI=1.38-4.75) or GSTT1 positive $(\mathrm{OR}=2.00 ; 95 \% \mathrm{CI}=1.05-3.83)$ genotypes. Moreover, risk was decreased in alcohol users carrying the GSTT1 null $(\mathrm{OR}=0.39 ; 95 \% \mathrm{CI}=0.16-0.97)$ genotype. Conclusion: This study suggests that variants of GSTM1 and GSTT1 may not be risk factors for breast cancer development among Filipinos. However, the risk may be increased when these genotypes were combined with lifestyle or environmental factors.
\end{abstract}

Keywords: Breast cancer- GSTM1-GSTT1-genetic polymorphism

Asian Pac J Cancer Prev, 20 (2), 529-535

\section{Introduction}

Polymorphism is a genetic variation resulting in the occurrence of several different forms or types of individuals among the members of a single species. One of the most widely known types of genetic polymorphisms among people is the single nucleotide polymorphism (SNP), which involves a variation at a single position in a DNA sequence and occurs in more than one percent of the general population. SNPs have been found to help predict an individual's response to certain drugs, susceptibility to environmental factors, and risk of developing diseases including cancer (Erichsen and Chanock, 2004).

Genes that encode xenobiotic metabolizing enzymes (XMEs) are being reviewed continuously due to their essential functions in the detoxification of toxic compounds implicated in carcinogenesis (López-Cimam et al., 2012). The reactions catalyzed by these enzymes are classified into phase I and phase II reactions. Phase I system utilizes enzymes that initiate the detoxification process by transforming lipid-soluble substances into water-soluble compounds through the introduction of polar and reactive groups into the incoming substrate
(Guengerich, 2001). Meanwhile, phase II system is responsible for conjugating the compounds modified and activated in phase I to specific substrates, yielding more polar and less toxic groups (Ford et al., 2000).

Among the most widely reviewed genes encoding the phase II detoxifying enzymes are glutathione S-transferase $\mu 1$ (GSTM1) and glutathione S-transferase $\theta 1$ (GSTT1). These genes are implicated in the conjugation of numerous carcinogenic compounds to excretable hydrophilic compounds (Hishida et al., 2005). However, null alleles of these genes corresponding to the deletion of whole protein-coding region have been identified to exist and are common across major human populations (Agúndez and Ladero, 2008). Individuals who completely lack GSTM1 and GSTT1 enzyme activity due to the inherited homozygous loss of these genes are more likely to have a higher risk of acquiring cancer (Ford et al., 2000).

Meta-analyses have shown the association of polymorphisms in GSTM1 and GSTT1 with increased breast cancer risk in Asians, most notably in Chinese populations (Tang et al., 2015; Xiao et al., 2015; Song et al., 2016). Numerous studies have also reported the possible association of deletions in GSTM1 and GSTT1 
with the risk of developing other cancer types, including colorectal cancer in Caucasians (Economopoulos and Sergentanis, 2010), lung cancer in African-Americans, Japanese, Swedes, and South Indians (Ford et al., 2000; Sunaga et al., 2002; Alexandrie et al., 2004; Leelakumari et al., 2005), acute lymphoblastic leukemia in Thai (Pakakasama et al., 2005), and myeloid leukemia in non-Hispanic Caucasians (Davies et al., 2000).

On the contrary, several studies have reported the absence of association of GSTM1 and GSTT1 polymorphisms with malignancies of the breast, colon, lung, prostate, and chronic myelogenous leukemia among Icelanders (Gudmundsdottir et al., 2001), Chinese (Economopoulos and Sergentanis, 2010), Greeks (Dialyna et al., 2003), and Japanese (Nakazato et al., 2003; Hishida et al., 2005), respectively. Acute lymphoblastic leukemia has been associated with GSTM1 null but not GSTT1 null genotypes in Filipino children (Rimando et al., 2008).

Those studies indicate that the association of polymorphisms in the GSTM1 and GSTT1 genes with cancer is tumor site- and race-dependent. Hence, this study analyzed the association of polymorphisms in the GSTM1 and GSTT1 genes in a set of Filipino breast cancer cases and matched clinically healthy controls. The results of the molecular analyses were also associated with other risk factors for breast cancer.

\section{Materials and Methods}

\section{Study Subjects}

Prior to the execution of this study, ethical clearances were secured from the Institutional Review Board (IRB) of the University of Santo Tomas Hospital (USTH) in Manila (Protocol Reference No. IRB-MD-09-2015-133) and the Mariano Marcos Memorial Hospital and Medical Center (MMMH-MC) in Ilocos Norte (RERC Protocol Nos. MMMH-RERC-15-005 and MMMH-RERC-15-006), Philippines. A total of 136 Filipino patients with histologically confirmed breast cancer, seen at the USTH and MMMH-MC from December 2015 to July 2016 were recruited for this study. The cancer cases were age- $( \pm 2$ years) and sex-matched with clinically healthy controls who were not suspected to have any type of malignancy. All participants gave their written informed consent and were asked to accomplish through interview by a member of the research team a standardized questionnaire inquiring on their risk factors. Clinical data of the cases were retrieved from medical records and histopathologic reports.

Genotyping of GSTM1 and GSTT1 Genetic Polymorphisms Genomic DNA was isolated from peripheral blood leukocytes of cancer cases and controls using ReliaPrep ${ }^{\mathrm{TM}}$ Blood gDNA Miniprep System (Promega, Madison, USA), following the manufacturer's protocol. Genotyping for GSTM1 and GSTT1 was carried out by multiplex polymerase chain reaction (PCR) as described (Rimando et al., 2008) but with minor modifications. The primer sequences used for the detection of GSTM1 and GSTT1 genotypes were as follows: GSTM1 (219 bp): 5'-GAACTCCCTGAAAAGCTAAAGC-3' (forward) and 5'-GTTGGGCTCAAATATACGGTGG-3' ( $\mathrm{reverse}$ ); GSTT 1 ( 459 b p ) : 5'-TTCCTTACTGGTCCTCACATCTC-3' (forward) and 5' - TCACCGGATCATGGCCA GCA - 3' (reverse); and albumin (350 b p): 5'-GCCCTCTGCTAACAAGTCCTAC-3' (forward) and 5'-GCCCTAAAAAGAAAATCGCCAATC-3' (reverse). A total PCR reaction volume of $20 \mu \mathrm{L}$ containing 25 units/mL Taq DNA polymerase, $200 \mu \mathrm{M}$ dNTPs, $1.5 \mathrm{mM}$ $\mathrm{MgCl}_{2}, 0.25 \mu \mathrm{M}$ of each primer, nuclease-free water, and $89 \mathrm{ng}$ of genomic DNA was prepared. The desired genes were amplified under the following PCR conditions: $95^{\circ} \mathrm{C}$ $(1 \mathrm{~min}), 60^{\circ} \mathrm{C}(1 \mathrm{~min}), 72^{\circ} \mathrm{C}(1 \mathrm{~min})$ for 40 cycles, with a final extension step at $72^{\circ} \mathrm{C}$ for $10 \mathrm{~min}$ in a PTC-200 thermal cycler (MJ Research, Inc., Waltham, USA). All PCR products were separated by electrophoresis on a $1 \%$ agarose gel containing SYBR ${ }^{\text {TM }}$ Safe DNA gel stain (Thermo Fisher Scientific, Waltham, USA).

\section{Statistical Analysis}

To determine the prevalence of GSTM1 and GSTT1 genotypes, genotype frequencies were computed, including deviations from the Hardy-Weinberg Equilibrium (HWE). The Pearson $\chi^{2}$ test was used to compare the differences in genotype frequencies between breast cancer cases and controls, while the relative risks of genotypes for breast cancer cases were determined by computing for the crude odds ratio (OR) with a 95\% confidence interval (CI). GSTM1 and GSTT1 genotypes were further correlated with other well-established risk factors for breast cancer.

\section{Results}

This study performed GSTM1 and GSTT1 genotyping in 136 breast cancer cases and sex- and age-matched 136 clinically healthy controls by multiplex PCR. The presence of a 219 bp GSTM1 (Figure 1a) or a 459 bp GSTT1 (Figure 1b) PCR product, with reference to $350 \mathrm{bp}$ albumin (positive internal control) indicates a "positive" genotype, while their absence indicates a "null" genotype. Since this study used conventional genotyping, it was not able to distinguish GSTT1 and GSTM1 positive genotypes as heterozygous or homozygous genotypes.

There was no significant difference $(\mathrm{p}>0.05)$ in the frequency of GSTM1 null genotype (Figure 2a) between cases $(n=78 ; 57.4 \%)$ and controls $(n=93 ; 68.4 \%)$. Similarly, frequency of GSTT1 null genotype (Figure $2 b)$ was not significantly different $(\mathrm{p}>0.05)$ between cases $(\mathrm{n}=61 ; 44.9 \%)$ and controls $(\mathrm{n}=59 ; 43.4 \%)$. The observed GSTM1 and GSTT1 genotype frequencies did not significantly deviate from their expected frequencies, thus, they are consistent with the Hardy-Weinberg equilibrium.

This study also determined the combined effect of the genotypic variants with lifestyle factors and family history of cancer. Only passive smoking was shown to be associated with increased risk of developing breast cancer. Among the cases carrying the GSTM1 null genotype, the passive smokers had higher risk $(\mathrm{OR}=2.56$; $95 \%$ $\mathrm{CI}=1.38-4.75)$ compared to active smokers (Table 1). A two-fold increased risk $(\mathrm{OR}=2.00 ; 95 \% \mathrm{CI}=1.05-3.83)$ was also seen in GSTT1 positive cases exposed to passive 
DOI:10.31557/APJCP.2019.20.2.529

GSTM1 and GSTT1 Genes and Breast Cancer

Table 1. Comparison of Relative Risks of Breast Cancer Cases and Controls with Combinations of GSTM1 Positive and Null Genotypes and Risk Factors

\begin{tabular}{|c|c|c|c|c|c|c|c|c|}
\hline \multirow[t]{2}{*}{ Characteristics } & \multicolumn{4}{|c|}{ GSTM1 positive } & \multicolumn{4}{|c|}{ GSTM1 null } \\
\hline & $\begin{array}{l}\text { Cases } \\
\mathrm{n}(\%)\end{array}$ & $\begin{array}{c}\text { Controls } \\
\text { n (\%) }\end{array}$ & OR $(95 \% \mathrm{CI})^{*}$ & p-value $\dagger$ & $\begin{array}{l}\text { Cases } \\
\mathrm{n}(\%)\end{array}$ & $\begin{array}{c}\text { Controls } \\
\text { n }(\%)\end{array}$ & OR $(95 \% \mathrm{CI})^{*}$ & p-value $\dagger$ \\
\hline \multicolumn{9}{|l|}{ Alcohol Use } \\
\hline Drinker & $8(13.8)$ & $8(18.6)$ & $0.70(0.24-0.04)$ & 0.51 & $10(12.8)$ & $22(23.7)$ & $0.47(0.21-1.08)$ & 0.07 \\
\hline Non-drinker & $50(86.2)$ & $35(81.4)$ & 1 & & $68(87.2)$ & $71(76.3)$ & 1 & \\
\hline \multicolumn{9}{|l|}{ Tobacco Use } \\
\hline \multicolumn{9}{|l|}{ Active } \\
\hline Smoker & $6(10.3)$ & $4(9.3)$ & $1.13(0.30-4.26)$ & 0.86 & $6(7.7)$ & $7(7.5)$ & $1.02(0.33-3.18)$ & 0.97 \\
\hline Non-smoker & $52(89.7)$ & $39(90.7)$ & 1 & & $72(92.3)$ & $86(92.5)$ & 1 & \\
\hline \multicolumn{9}{|l|}{ Passive } \\
\hline Yes & $29(50.0)$ & $18(41.9)$ & $1.39(0.63-3.08)$ & 0.42 & $49(62.8)$ & $37(39.8)$ & $2.56(1.38-4.75)$ & 0.003 \\
\hline No & $29(50.0)$ & $25(58.1)$ & 1 & & $29(37.2)$ & $56(60.2)$ & 1 & \\
\hline \multicolumn{9}{|c|}{ Family History of Cancer } \\
\hline \multicolumn{9}{|l|}{ Immediate } \\
\hline Yes & $9(15.5)$ & $11(25.6)$ & $0.53(0.20-1.43)$ & 0.21 & $17(21.8)$ & $19(20.4)$ & $1.09(0.52-2.27)$ & 0.83 \\
\hline No & $49(84.5)$ & $32(74.4)$ & 1 & & $61(78.2)$ & $74(79.6)$ & 1 & \\
\hline \multicolumn{9}{|l|}{ Extended } \\
\hline Yes & $17(29.3)$ & $14(32.6)$ & $0.86(0.37-2.01)$ & 0.73 & $31(39.7)$ & $25(26.9)$ & $1.79(0.94-3.42)$ & 0.08 \\
\hline No & $41(70.7)$ & $29(67.4)$ & 1 & & $47(60.3)$ & $68(73.1)$ & 1 & \\
\hline
\end{tabular}

*OR, crude odds ratio at $95 \%$ confidence interval; $†$ Chi-squared test, two-sided $p$-value $<0.05$

smoke (Table 2).

\section{Discussion}

Breast cancer remains to be the leading cause of cancer among women worldwide, with over 2 million new cases resulting in more than 600,000 deaths each year. It is further estimated that by 2050, around 3.2 million women worldwide will be affected by breast cancer (Moore et al., 2008). In the Philippines, 14,955 newly diagnosed cases were reported in Metro Manila and Rizal Province between 2008 to 2012 (Bray et al., 2017).

Several studies have shown the potential association of genetic polymorphisms with susceptibility to various
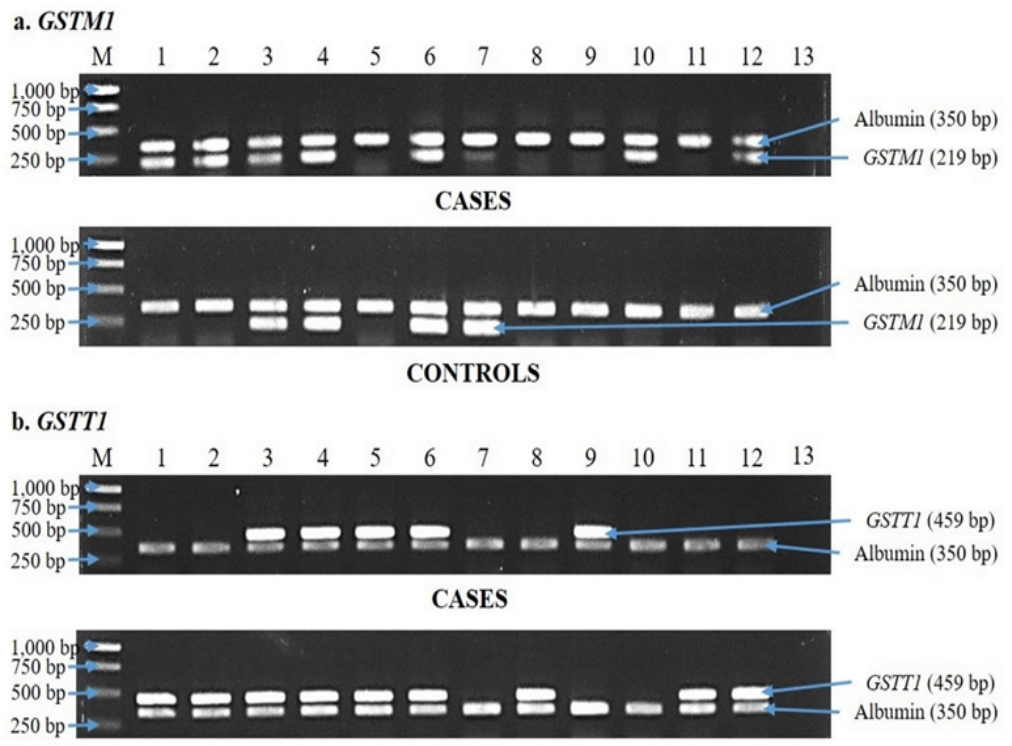

CONTROLS

Figure 1. Representative Results for (a) GSTM1 and (b) GSTT1 Genotyping by PCR Method. DNA isolates from breast cancer cases and controls were subjected to duplex PCR using GSTM1, GSTT1, and albumin primers. (a) GSTM1. Cases: Lane M: marker; lanes 5, 7 to 9, and 11: GSTM1 null; lanes 1 to 4, 6, 10, and 12: GSTM1 positive; lane 13: negative control. Controls: lanes 1, 2, 5, and 8 to 12: GSTM1 null; lanes 3, 4, 6, and 7: GSTM1 positive. (b) GSTT1. Cases: Lane M: marker; lanes 1, 2, 7, 8, and 10 to 12: GSTT1 null; lanes 3 to 6 and 9: GSTT1 positive; lane 13: negative control. Controls: lanes 7, 9, and 10: GSTT1 null; lanes 1 to 6, 8, 11, and 12: GSTT1 positive. 
Table 2. Comparison of Relative Risks of Breast Cancer Cases and Controls with Combinations of GSTT1 Positive and Null Genotypes and Risk Factors

\begin{tabular}{|c|c|c|c|c|c|c|c|c|}
\hline \multirow[t]{2}{*}{ Characteristics } & \multicolumn{4}{|c|}{ GSTT1 positive } & \multicolumn{4}{|c|}{ GSTT1 null } \\
\hline & $\begin{array}{l}\text { Cases } \\
\mathrm{n}(\%)\end{array}$ & $\begin{array}{c}\text { Controls } \\
\mathrm{n}(\%)\end{array}$ & OR $(95 \% \mathrm{CI}) *$ & p-value $\dagger$ & $\begin{array}{l}\text { Cases } \\
\mathrm{n}(\%)\end{array}$ & $\begin{array}{c}\text { Controls } \\
\text { n }(\%)\end{array}$ & OR $(95 \% \mathrm{CI}) *$ & p-value $\dagger$ \\
\hline \multicolumn{9}{|l|}{ Alcohol Use } \\
\hline Drinker & $8(10.7)$ & $18(23.4)$ & $0.39(0.16-0.97)$ & 0.04 & $10(16.4)$ & $12(20.3)$ & $0.77(0.30-1.94)$ & 0.58 \\
\hline Non-drinker & $67(89.3)$ & $59(76.6)$ & 1 & & $51(83.6)$ & $47(79.7)$ & 1 & \\
\hline \multicolumn{9}{|l|}{ Tobacco Use } \\
\hline \multicolumn{9}{|l|}{ Active } \\
\hline Smoker & $10(13.3)$ & $9(11.7)$ & $1.16(0.44-3.04)$ & 0.76 & $2(3.3)$ & $2(3.4)$ & $0.97(0.13-7.09)$ & 0.97 \\
\hline Non-smoker & $65(86.7)$ & $68(88.3)$ & 1 & & $59(96.7)$ & $57(96.6)$ & 1 & \\
\hline \multicolumn{9}{|l|}{ Passive } \\
\hline Yes & $40(53.3)$ & $28(36.4)$ & $2.00(1.05-3.83)$ & 0.04 & $38(62.3)$ & $27(45.8)$ & $1.96(0.95-4.06)$ & 0.07 \\
\hline No & $29(46.7)$ & $49(63.6)$ & 1 & & $23(37.7)$ & $32(54.2)$ & 1 & \\
\hline \multicolumn{9}{|c|}{ Family History of Cancer } \\
\hline \multicolumn{9}{|l|}{ Immediate } \\
\hline Yes & $16(21.3)$ & $15(19.5)$ & $1.12(0.51-2.47)$ & 0.78 & $11(18.0)$ & $15(25.4)$ & $0.65(0.27-1.55)$ & 0.33 \\
\hline No & $59(78.7)$ & $62(80.5)$ & 1 & & $50(82.0)$ & $44(74.6)$ & 1 & \\
\hline \multicolumn{9}{|l|}{ Extended } \\
\hline Yes & $27(36.0)$ & $24(31.2)$ & $1.24(0.63-2.44)$ & 0.53 & $21(34.4)$ & $16(27.1)$ & $1.41(0.65-3.08)$ & 0.39 \\
\hline No & $48(64.0)$ & $53(68.8)$ & 1 & & $40(65.6)$ & $43(72.9)$ & 1 & \\
\hline
\end{tabular}

*OR, crude odds ratio at $95 \%$ confidence interval; $\uparrow$ Chi-squared test, two-sided $p$-value $<0.05$
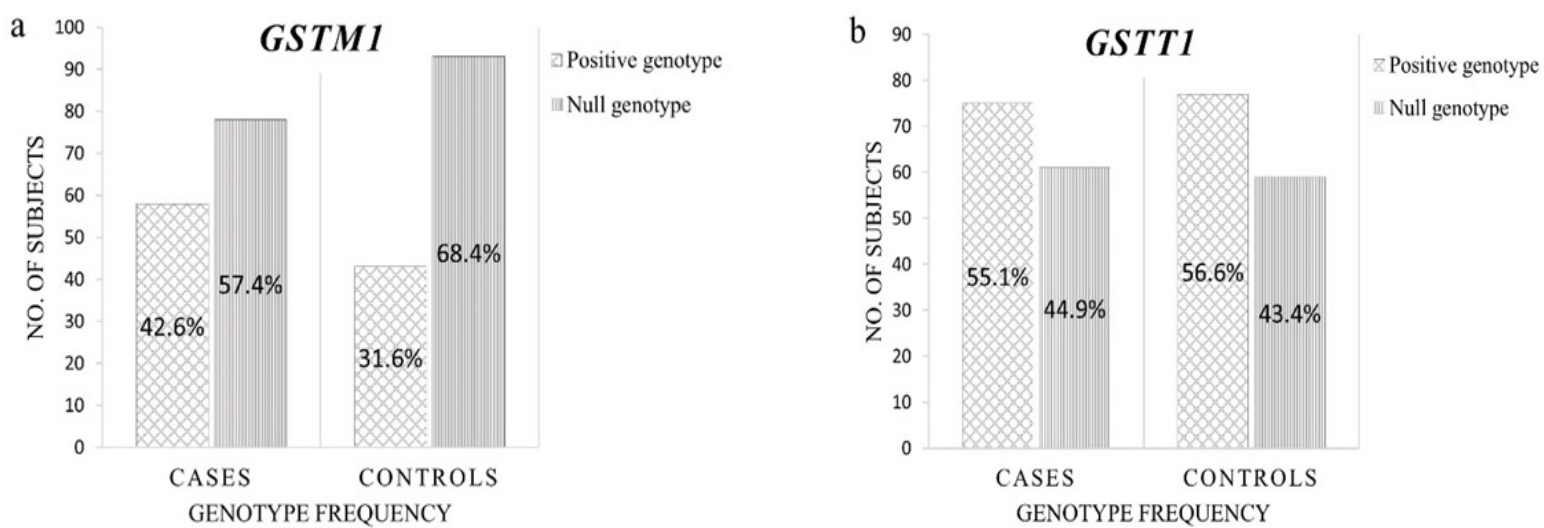

Figure 2. Comparison of GSTM1 and GSTT1 Genotype Frequencies. Frequencies were determined from the distribution of the positive and null genotypes of GSTM1 and GSTT1 to breast cancer cases and controls. (a) The frequencies of the GSTM1 positive genotype for cases and controls were $42.6 \%(\mathrm{n}=58)$ and $31.6 \%(\mathrm{n}=43)$, respectively, while the frequencies of the GSTM1 null genotype for cases and control were $57.4 \%(\mathrm{n}=78)$ and $68.4 \%(\mathrm{n}=93)$, respectively. (b) The frequencies of the GSTT1 positive genotype for cases and controls were $55.1 \%(\mathrm{n}=75)$ and $56.6 \%(\mathrm{n}=77)$, respectively, while the frequencies of the GSTT1 null genotype for cases and control were $44.9 \%(\mathrm{n}=61)$ and $43.4 \%$ $(n=59)$, respectively.

types of cancer. Among the genes being extensively studied are GSTM1 and GSTT1, which belong to the glutathione S-transferase (GST) supergene family. GSTs primarily catalyze the oxidation of glutathione, which subsequently detoxifies xenobiotics and carcinogens to make them easily excretable (Boyer, 1989). The GSTM1 and GSTT1 genes encode the GST $\mu$ (mu) and $\theta$ (theta) isoenzymes, GSTM1 and GSTT1, respectively. The GSTM1 isoenzyme is implicated in the cleansing of activated carcinogens such as hydroxylated metabolites of benzo[a]pyrene, epoxides, and polycyclic aromatic hydrocarbons (PAHs) (Ketterer et al., 1992), rendering these compounds more water-soluble for easy excretion outside the cell. The GSTT1 isoenzyme is involved in the detoxification of numerous low molecular weight toxins such as ethylene oxides and butadienes, and haloalkanes including dichloromethanes (Guengerich et al., 1995; Hayes et al., 2005).

It has been proven that homozygous deletions of the polymorphic GSTM1 and GSTT1 genes result in 
the loss of catalytic activity of the enzymes they encode correspondingly, leading to the decreased ability of the cells to detoxify various xenobiotic or genotoxic agents (Norppa, 2004). Exhaustion of glutathione to 20-30\% of the total glutathione level can weaken defense against xenobiotics, causing harm to several cellular processes (Reed, 1990). Hence, depletion of glutathione, which may be caused by the combined actions of all the GSTs, can expose the cells to damaging effects of oxidative stress and related mutagenic lesions.

Results of this study show no significant difference in the frequencies of GSTM1 and GSTT1 null genotypes between Filipino breast cancer cases and clinically healthy controls. A slightly higher prevalence of the GSTM1 null genotype in controls (68.4\%) compared to the cases $(57.4 \%$ ) (Figure $2 \mathrm{a}$ ) was seen in this study. Seemingly, the loss of the GSTM1 gene might even offer a protective effect for the cell. This observation might be attributed to the interdependence among detoxifying and/ or DNA-repair genes (Roodi et al., 2004). While studies have demonstrated that complete absence of GSTT1 results in diminished detoxification capabilities (Pemble et al., 1994; Wiencke et al., 1995), this study shows lack of association between the GSTT1 null genotype and the risk of developing breast cancer (Figure $2 b$ ).

Findings of this study are contrary to what have been seen among Indians (Kimi et al., 2016), Brazilians (Possuelo et al., 2013), Caucasians (Zheng et al., 2002), Dutch (van der Hel et al., 2004), and French (LizardNacol et al., 1999). The lack of association of GSTM1 null genotype with breast cancer has also been seen in Iranian (Saadat et al., 2001), Lebanese (Zgheib et al., 2013), Pakistani (Sohail et al., 2013), Taiwanese (Chang et al., 2006), Icelandic (Gudmundsdottir et al., 2001), Mexican (Rodriguez et al., 2014), and Caucasian and AfricanAmerican (Van Emburgh et al., 2008) populations. The lack of association between GSTT1 null genotype and breast cancer has been seen in Dutch (van der Hel et al., 2004), Lebanese (Zgheib et al., 2013), Pakistani (Sohail et al., 2013), Icelandic (Gudmundsdottir et al., 2001), Mexican (Rodriguez et al., 2014), Caucasian and African-American (Van Emburgh et al., 2008) and Iranian (Hashemi et al., 2012) populations. Association of GSTT1 null genotype with breast cancer have been observed in studies from Northeast India (Kimi et al., 2016), Iowa (Zheng et al., 2002), Southern Taiwan (Chang et al., 2006), and China (Tang et al., 2015; Xiao et al., 2015; Song et al., 2016).

Although this study shows lack of association of the GSTM1 and GSTT1 null genotypes with breast cancer, it should be noted that an interplay of genetic predisposition with environmental and lifestyle factors plays a role in increased susceptibility to breast cancer. Reproductive factors, which include nulliparity, family history of breast cancer, use of oral contraceptives, and age at menopause and menarche, are well-established risk factors for breast cancer. Lifestyle practices such as tobacco smoking, alcohol consumption, sedentary existence, and fatty diet are also among the predisposing factors (Ngelangel et al., 2009).

Passive smoking appears to increase the risk of developing breast cancer among Filipinos carrying the GSTM1 null (Table 1) and GSTT1 positive (Table 2) genotypes. Several compounds had been identified in secondhand tobacco smoke to be associated with cancer development (Margham et al., 2016). Our finding on the association of passive but not active smoking with risk of developing breast cancer may be attributed to the fact that the fume inhaled by passive smokers come from the unfiltered lighted end of the cigarette (sidestream smoke), hence, it contains more carcinogenic compounds than inhaled or mainstream smoke. Active smokers inhale filtered mainstream smoke that have reduced amount of tar and nicotine (Kapp, 2005). The minute size of nitrosamines and other carcinogens allow them to remain longer in the atmosphere. Vapor-phase constituents of passive smoke compared to particulate-phase constituents of mainstream smoke can also easily access the cells of the body and become readily absorbed into the blood and lymph systems (Li et al., 2015). Apparently, the GSTT1 positive genotype combined with alcohol consumption showed a protective effect against the risk of breast cancer. This suggests the possibility that the GSTT1 positive genotype is able to compensate the harmful effects of excessive alcohol consumption, or this particular gene might be interacting with other detoxifying genes that are encoding phase I enzymes or phase II enzymes apart from GSTs (Leelakumari et al., 2005).

In conclusion, no association was found between GSTM1 and GSTT1 genetic polymorphisms and the risk of developing breast cancer among Filipinos. However, this risk was modified when individual genotypes of GSTM1 and GSTT1 were combined with risk factors such as alcohol use and passive smoking. Nevertheless, it is recommended that the number of participants is increased to further validate the results of this study. It is further suggested to recruit participants from other parts of the country in order to accurately represent the entire Filipino population.

\section{Declarations of Interest}

The authors declare no conflict of interest.

\section{References}

Agúndez J, Ladero J (2008). Glutathione S-transferase GSTT1 and GSTM1 allozymes: beyond null alleles. Pharmacogenomics, 9, 359-63.

Alexandrie A, Nyberg F, Warholm M, Rannug A (2004). Influence of CYP1A1, GSTM1, GSTT1, and NQO1 genotypes and cumulative smoking dose on lung cancer risk in a Swedish population. Cancer Epidemiol Biomarkers Prev, 13, 908-14.

Bray F, Colombet M, Mery L, et al (2017). Cancer Incidence in Five Continents, Vol. XI. International Agency for Research on Cancer, Lyon.

Boyer T (1989). The glutathione S-transferases: Na update. Hepatology, 9, 486-96.

Chang T, Wang S, Guo Y, et al (2006). Glutathione S-transferase polymorphisms associated with risk of breast cancer in southern Taiwan. Breast J, 15, 754-61.

Davies S, Robison L, Buckley J, et al (2000). Glutathione S-transferase polymorphisms in children with myeloid leukemia: a children's cancer group study. Cancer Epidemiol Asian Pacific Journal of Cancer Prevention, Vol 20 
Biomarkers Prev, 9, 563-6.

Dialyna I, Miyakis S, Georgatou N, Spandidos D (2003). Genetic polymorphisms of CYP1A1, GSTM1 and GSTT1 genes and lung cancer risk. Oncol Rep, 10, 1829-35.

Economopoulos K, Sergentanis T (2010). GSTM1, GSTT1, GSTP1, GSTA1 and colorectal cancer risk: a comprehensive meta-analysis. Eur J Cancer, 46, 1617-31.

Erichsen H, Chanock S (2004). SNPs in cancer research and treatment. Br J Cancer, 90, 747-51.

Ford J, Li Y, O'Sullivan M, et al (2000). Glutathione S-transferase M1 polymorphism and lung cancer risk in African-Americans. Carcinogenesis, 21, 1971-5.

Gudmundsdottir K, Tryggvadottir L, Eyfjord J (2001). GSTM1, GSTT1, and GSTP1 genotypes in relation to breast cancer risk and frequency of mutations in the p53 gene. Cancer Epidemiol Biomarkers Prev, 10, 1169-73.

Guengerich F, Thier R, Persmark M, et al (1995). Conjugation of carcinogens by theta class glutathione s-transferases: mechanisms and relevance to variations in human risk. Pharmacogenetics, 5, 103-7.

Guengerich F (2001). Common and uncommon cytochrome P450 reactions related to metabolism and chemical toxicity. Chem Res Toxicol, 14, 611-50.

Hashemi M, Eskandari-Nasab E, Fazaeli A, et al (2012). Association between polymorphisms of glutathione S-transferase genes (GSTM1, GSTP1 and GSTT1) and breast cancer risk in a sample Iranian population. Biomark Med, 6, 797-803.

Hayes J, Flanagan J, Jowsey I (2005). Glutathione transferases. Annu Rev Pharmacol Toxicol, 463, 51-88.

Hishida A, Terakura S, Emi N, et al (2005). GSTT1 and GSTM1 deletions, NQO1 C609T polymorphism and risk of chronic myelogenous leukemia in Japanese. Asian Pac J Cancer Prev, 6, 251-5.

Kapp R (2005). Encyclopedia of Toxicology. In 'Tobacco Smoke', Ed Wexler P. Elsevier, London, pp 200-2.

Ketterer B, Harris J, Talaska G, et al (1992). The human glutathione S-transferase supergene family, its polymorphism, and its effects on susceptibility to lung cancer. Environ Health Perspect, 98, 87-94.

Kimi L, Ghatak S, Yadav R, et al (2016). Relevance of GSTM1, GSTT1 and GSTP1 gene polymorphism to breast cancer susceptibility in Mizoram Population, Northeast India. Biochem Genet, 54, 41-9.

Leelakumari S, Syamala V, Hariharan S, Madhavan JD, Ankathil R (2005). Possible risk modification by CYP1A1, GSTM1 and GSTT1 gene polymorphisms in lung cancer susceptibility in a South Indian population. J Hum Genet, 50, 618-27.

Li B, Wang L, Lu M, et al (2015). Passive smoking and breast cancer risk among non-smoking women: a case-control study in China. PLoS One, 10, 1-14.

Lizard-Nacol S, Coudert B, Colosetti P, et al (1999). Glutathione S-transferase M1 null genotype: lack of association with tumour characteristics and survival in advanced breast cancer. Breast Cancer Res, 1, 81-7.

López-Cimam M, Álvarez-Avellón S, Pascual T, Fernández-Somoano A, Tardón A (2012). Genetic polymorphisms in CYP1A1, GSTM1, GSTP1 and GSTT1 metabolic genes and risk of lung cancer in Asturias. $B M C$ Cancer, 12, 1-11.

Margham J, McAdam K, Forster M, et al (2016). Chemical composition of aerosol from an e-cigarette: a quantitative comparison with cigarette smoke. Chem Res Toxicol, 29, 1662-78.

Moore MA, Manan AA, Chow KY, et al (2008). Cancer epidemiology and control in peninsular and island
South-East Asia - past, present and future. Asian Pac J Cancer Prev, 11, 81-98.

Nakazato H, Suzuki K, Matsui H, et al (2003). Association of genetic polymorphisms of glutathione-S-transferase genes (GSTM1, GSTT1 and GSTP1) with familial prostate cancer risk in a Japanese population. Anticancer Res, 23, 2897-902.

Ngelangel CA, Javelosa MAU, Cutiongco-de la Paz EM (2009). Epidemiological risk factors for cancers of the lung, breast, colon-rectum and oral cavity: a case-control study in the Philippines. Acta Med Philipp, 43, 29-34.

Norppa H (2004). Cytogenetic biomarkers and genetic polymorphisms. Toxicol Lett, 149, 309-34.

Pakakasama S, Mukda E, Sasanakul W, et al (2005). Polymorphisms of drug-metabolizing enzymes and risk of childhood acute lymphoblastic leukemia. Am J Hematol, 79, 202-5.

Pemble S, Schroeder K, Spencer S, et al (1994). Human glutathione S-transferase theta (GSTT1): cDNA cloning and the characterization of a genetic polymorphism. Biochem $J$, 300, 271-6.

Possuelo L, Peraça C, Eisanhardt M, et al (2013). Polymorphisms of GSTM1 and GSTT1 genes in breast cancer susceptibility: a case-control study. Rev Bras Ginecol Obstet, 35, 569-74.

Reed D (1990). Glutathione: toxicological implications. Annu Rev Pharmacol Toxicol, 30, 603-31.

Rimando M, Chua M, Yuson E, de Castro-Bernas G, Okamoto T (2008). Prevalence of GSTT1, GSTM1 and NQO1 (609C > T) in Filipino children with ALL (acute lymphoblastic leukaemia). Biosci Rep, 28, 117-24.

Rodriguez M, Mejia F, Lecourtois M, Dominguez V, Castillo J (2014). Influence of GSTM1, GSTT1 and GSTP1 polymorphisms on the development of breast cancer. $J$ Cancer Ther, 5, 552-9.

Roodi N, Dupont W, Moore J, Parl F (2004). Association of homozygous wild-type glutathione S-transferase M1 genotype with increased breast cancer risk. Cancer Res, 64, 1233-6.

Saadat I, Omidvari S, Saadat M (2001). Genetic polymorphism of the Glutathione S-transferase M1 and development of breast cancer. Iran Biomed J, 5, 21-5.

Sohail A, Kanwal N, Ali M, et al (2013). Effects of glutathioneS-transferase polymorphisms on the risk of breast cancer: a population-based case-control study in Pakistan. Environ Toxicol Pharmacol, 35, 143-53.

Song Z, Shao C, Feng C, et al (2016). Association of glutathione S-transferase T1, M1, and P1 polymorphisms in the breast cancer risk: a meta-analysis. Ther Clin Risk Manag, 12, 763-9.

Sunaga N, Kohno T, Yanagitani N (2002). Contribution of the NQO1 and GSTT1 polymorphisms to lung adenocarcinoma susceptibility. Cancer Epidemiol Biomarkers Prev, 11, 730-8.

Tang J, Zhou Q, Zhao F, et al (2015). Association of glutathione S-transferase T1, M1 and P1 polymorphisms in the breast cancer risk: a meta-analysis in Asian population. Int J Clin Exp Med, 8, 12430-47.

van der Hel O, Peeters P, Hein D, et al (2004). GSTM1 null genotype, red meat consumption and breast cancer risk (The Netherlands). Cancer Causes Control, 15, 295-303.

Van Emburgh B, Hu J, Levine E, et al (2008). Polymorphisms in CYP1B1, GSTM1, GSTT1 and GSTP1, and susceptibility to breast cancer. Oncol Rep, 19, 1311-21.

Wiencke J, Pemble S, Ketterer B, Kelsey K (1995). Gene deletion of glutathione S-transferase theta: correlation with induced genetic damage and potential role in endogenous mutagenesis. Cancer Epidemiol Biomarkers Prev, 4, 253-60. Xiao Z, Li Y, Guan Y, Li J (2015). GSTT1 polymorphism and 
breast cancer risk in the Chinese population: an updated meta-analysis and review. Int J Clin Exp Med, 8, 6650-7.

Zgheib N, Shamseddine A, Geryess E, et al (2013). Genetic polymorphisms of CYP2E1, GST, and NAT2 enzymes are not associated with risk of breast cancer in a sample of Lebanese women. Mutat Res, 747, 40-7.

Zheng W, Wen W, Gustafson D, et al (2002). GSTM1 and GSTT1 polymorphisms and postmenopausal breast cancer risk. Breast Cancer Res Treat, 74, 9-16.

\section{c) (i) (9)}

This work is licensed under a Creative Commons AttributionNon Commercial 4.0 International License. 